\title{
Pearls
}

\section{Pearls: How to Reduce and Fix Comminuted Posterior Acetabular Wall Fractures}

\author{
Berton R. Moed MD
}

$\mathrm{F}$ ractures of the posterior wall of the acetabulum are common, constituting approximately $25 \%$ of all acetabular fractures [2]. In addition, their diagnosis is straightforward using standard plain radiographs and CT scans. However, rather than consisting of one uncomplicated fracture fragment, the majority of posterior

A Note from the Editor-in-Chief:

We are pleased to present the next installment of "Pearls", a column in Clinical

Orthopaedics and Related Research ${ }^{\mathbb{R}}$. In this column, distinguished surgeons, scientists, or scholars share surgical or professional tips they use to help surmount important or interesting problems. We welcome reader feedback on all of our columns and articles; please send your comments to eic@clinorthop.org.

The author certifies that he, or any member of his immediate family, have no funding or commercial associations (eg, consultancies, stock ownership, equity interest, patent/ licensing arrangements, etc) that might pose a conflict of interest in connection with the submitted article.

All ICMJE Conflict of Interest Forms for authors and Clinical Orthopaedics and Related Research ${ }^{\circledR}$ editors and board members are on file with the publication and can be viewed on request.

The opinions expressed are those of the writers, and do not reflect the opinion or policy of Clinical Orthopaedics and Related Research $^{\circledR}$ or The Association of Bone and Joint Surgeons ${ }^{\circledR}$. wall fractures present in combination with intraarticular free fragments and/ or fragments of the articular surface that are impacted into the underlying cancellous bone along the margin of the posterior wall fracture line (marginal impaction) $[2,4,5]$. These comminuted intraarticular fractures (Fig. 1A-B) are challenging surgical cases, with many investigators reporting an unsatisfactory outcome in approximately $30 \%$ of cases [3, 6].

The most-crucial determinant of clinical success is the accuracy of the fracture reduction $[2,3,5]$. Nevertheless, maintaining reduction of intraarticular fracture fragments until solid union takes place is challenging. For extensive comminution, it is more demanding to maintain anatomical reduction unless additional support is provided for the intercalary osteochondral fragments. In addition, as the overlying posterior wall component is reduced, shifting of the potentially mobile interposed osteochondral frag-

B. R. Moed MD ( $\square)$

Department of Orthopaedic Surgery,

Saint Louis University School of

Medicine, 3635 Vista Ave.,

7th Floor Desloge Towers,

St. Louis, MO 63110, USA

e-mail: moedbr@slu.edu ments may occur. However, the use of a two-level reconstruction technique appears to provide the necessary stable fixation and is associated with the best results in terms of the incidence of posttraumatic osteoarthritis and clinical outcome $[1,4,5]$.

After the surgical approach is completed, exposing the posterior wall and column and clearing the joint of debris, each intraarticular fragment is carefully delineated. In the usual technique, the free osteochondral articular fragments and marginally impacted ones are reduced using the femoral head as a template and any remaining underlying bony defect is filled with structural bone graft material (Fig. 2). With the two-level technique, these intraarticular fragments are provisionally held in place with 1.6-mm Kirschner wires followed by application of the bone graft material (Fig. 3A-B). For definitive fixation, the Kirschner wires are subsequently exchanged for $2.0-\mathrm{mm}$ miniscrews or, preferably, $1.5-\mathrm{mm}$ bioabsorbable pegs (Fig. 4), commonly being approximately $40 \mathrm{~mm}$ in length. Multiple wires can be inserted in large osteochondral fragments, allowing sequential exchange to the definitive fixation and thereby minimizing the risk of reduction loss during the 
Fig. 1 (A) An intraoperative photograph shows the femora head (f) and an impacted and slightly comminuted articular (c). (B) A diagrammatic illustration shows a posterior wall acetabular fracture with marginal impaction and an osteochondral free fragment. (Published with permission from Berton R. Moed MD). surface with the underlying compressed cancellous bone
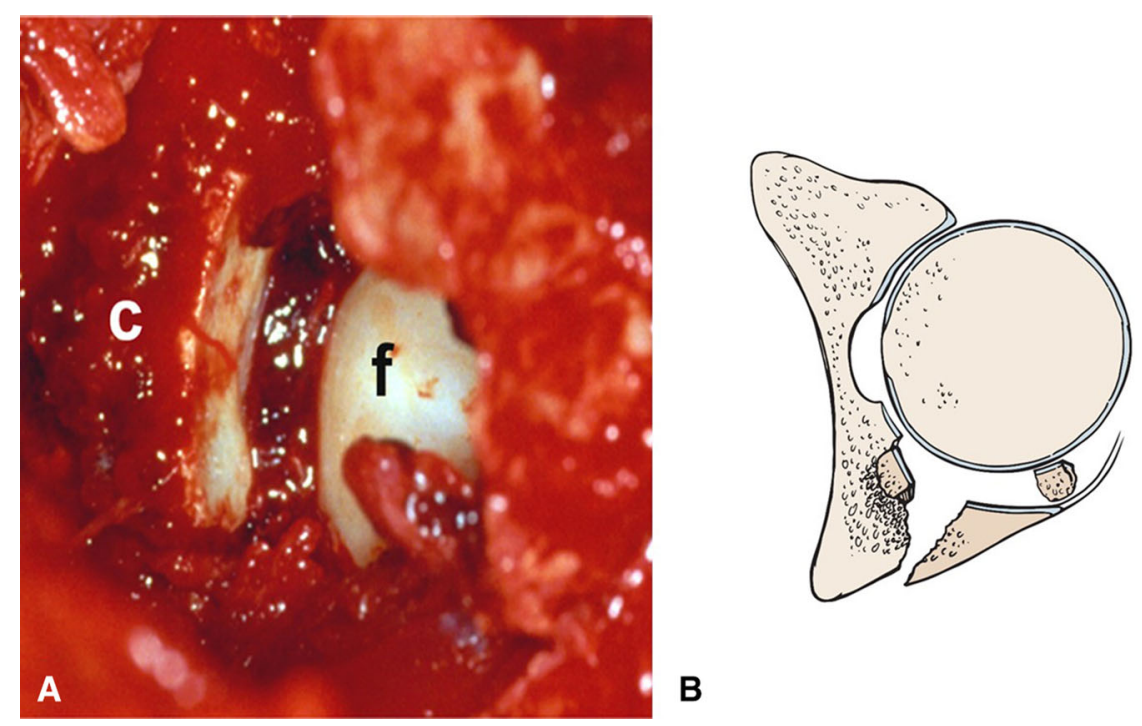

B

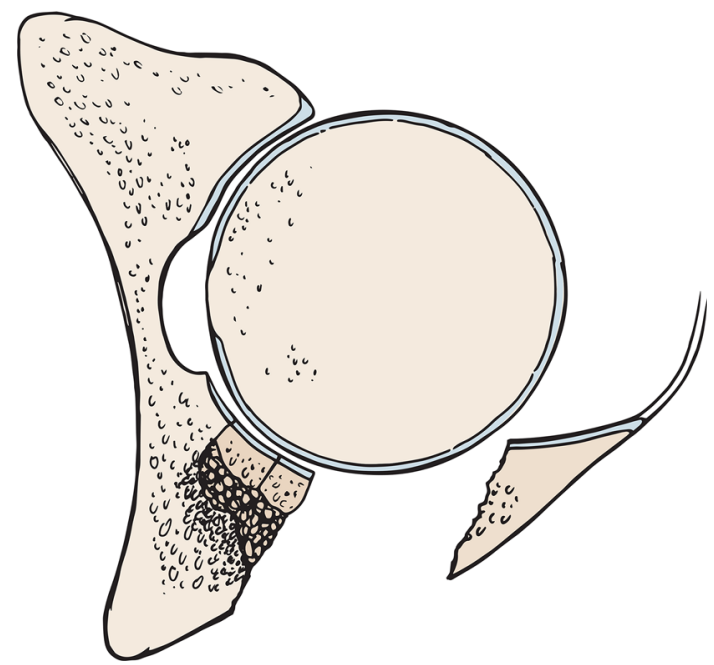

Fig. 2 A diagrammatic illustration after fracture fragment reduction and bone grafting is shown. (Published with permission from Berton R. Moed MD). exchange procedure. Reduction and fixation of the overlying posterior wall fragment (Fig. 5A-B) can follow without fear of displacing the underlying osteochondral components, completing the two-level fixation construct [1]. In this way, the best results can be attained.

\section{References}

1. Giannoudis PV, Tzioupis CC, Moed BR. Two-level reconstruction of comminuted posterior-wall fractures of the acetabulum. J Bone Joint Surg Br. 2007;89:503-509. 


\section{Pearls}

Fig. 3A-B (A) An

intraoperative photograph and (B) a diagrammatic illustration after fracture fragment reduction, temporary Kirschner wire fixation, and bone grafting are shown. (Published with permission from Berton $\mathrm{R}$. Moed MD).
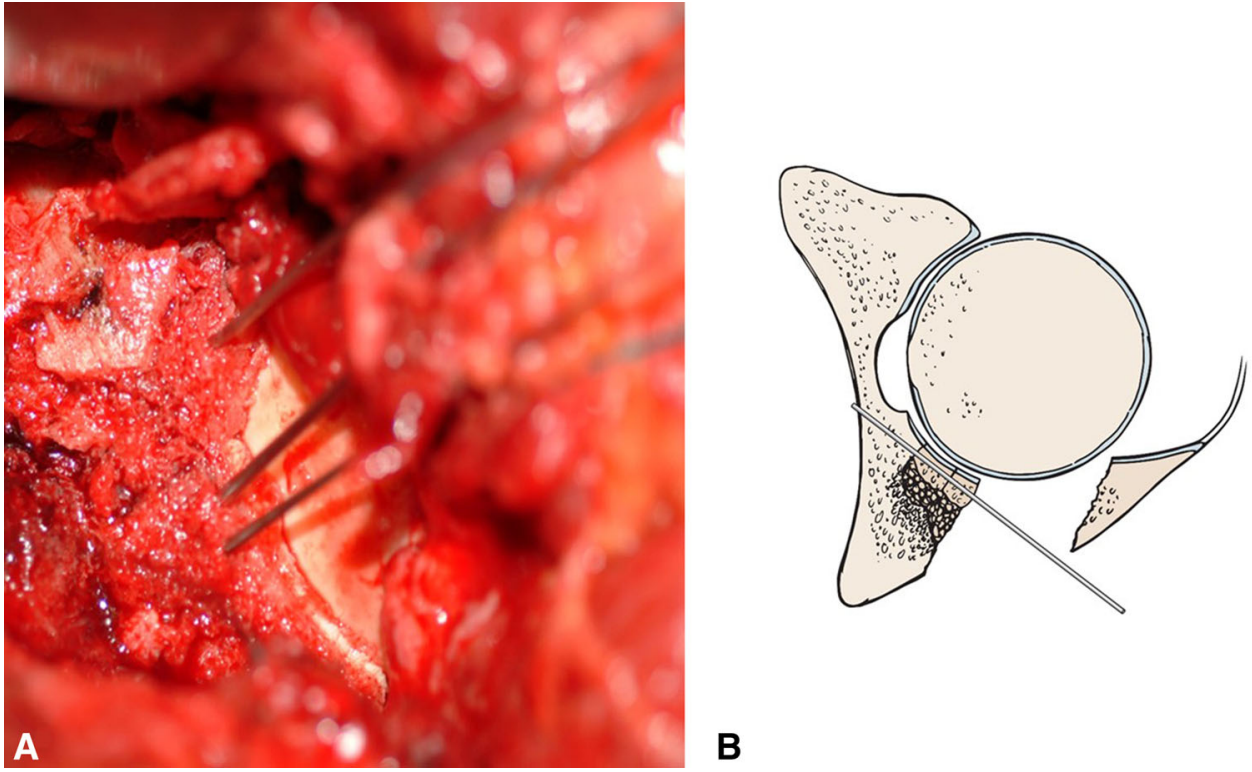

B

2. Letournel E, Judet R. Fractures of the Acetabulum. 2nd ed. Elson RA, translator, ed. New York, NY: SpringerVerlag; 1993:565-581.

3. Matta JM. Fractures of the acetabulum: Accuracy of reduction and clinical results in patients managed operatively within three weeks after injury. $J$ Bone Joint Surg Am. 1996;78:1632-1645.

4. Moed BR, Carr SEW, Gruson K, Watson JT, Craig JG. Computed tomography assessment of fractures of the posterior wall of the acetabulum after operative treatment. $J$ Bone Joint Surg Am. 2003;85:512522.

5. Moed BR, Carr SEW, Watson JT. Results of operative treatment of
Fig. 4 A diagrammatic illustration after exchange of the Kirschner wire for a 1.5-mm bioabsorbable peg is shown. (Published with permission from Berton R. Moed MD). 
Pearls
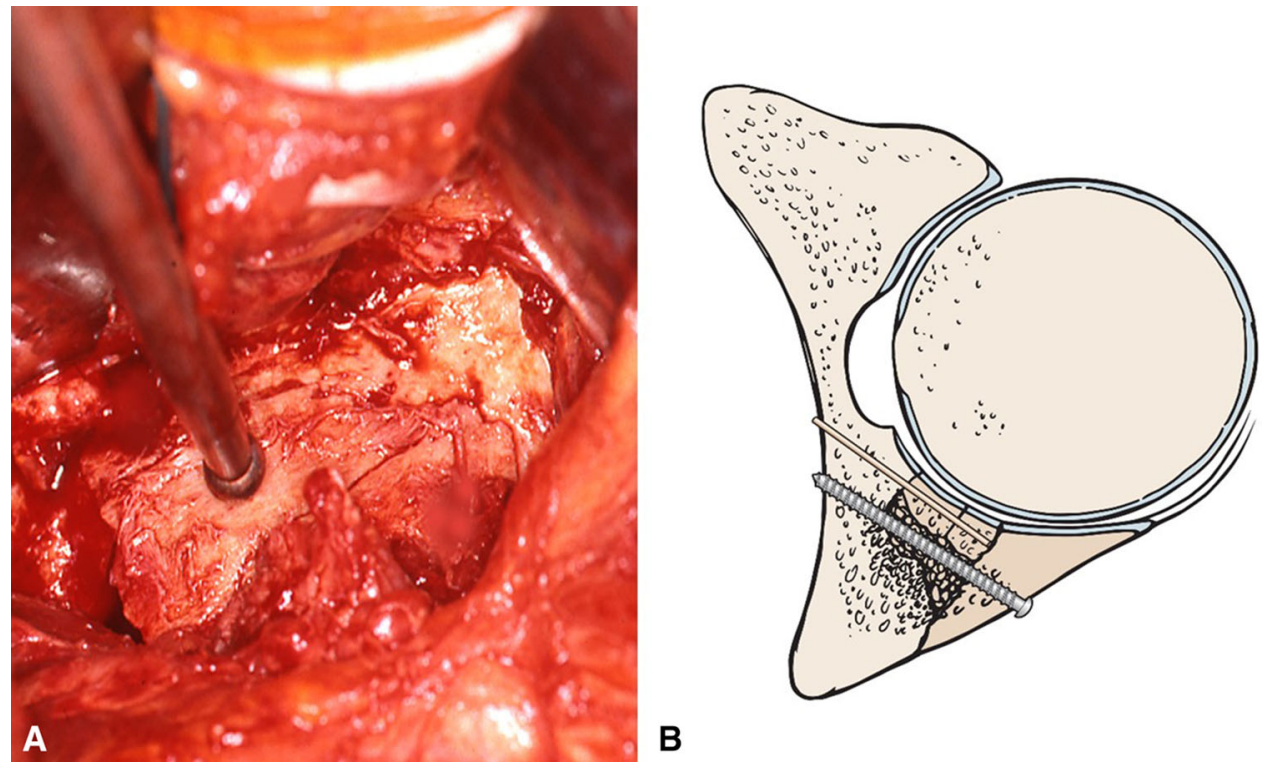

Fig. 5A-B (A) An intraoperative photograph shows the overlying posterior wall fragment reduced and held with the straight ball-spiked pusher, (B) which is followed, as shown diagrammatically, by its plate and screw fixation to complete the two-level fixation construct. (Published with permission from Berton R. Moed MD).

fractures of the posterior wall of the acetabulum. J Bone Joint Surg Am. 2002;84:752-758.
6. Saterbak AM, Marsh JL, Nepola JV, Brandser EA, Turbett T. Clinical failure after posterior wall acetabular fractures: The influence of initial fracture patterns. J Orthop Trauma. 2000;14:230-237. 